\title{
Aulas de ciências em laboratórios de informática: uma construção discursiva do monopólio participativo
}

\author{
Bruno de Oliveira-Jayme \\ University of Victoria \\ Giuliano Reis \\ University of Ottawa \\ Michiel van Eijck \\ Eindhoven University of Technology \\ Wolff-Michael Roth \\ University of Victoria
}

\section{Resumo}

No presente estudo, examinamos como a natureza das interações entre os membros de um grupo de estudantes durante uma atividade escolar mediada pelo uso de computadores não só é influenciada pela disposição física dos componentes do grupo, como também possibilita a ocorrência de monopolização. Utilizando uma perspectiva sociocultural da aprendizagem em conjunto com a análise do discurso como ferramentas de análise e interpretação dos dados, investigou-se as trocas verbais e não verbais entre participantes um grupo de trabalho numa sala de aula do ensino fundamental para discutir as consequências negativas de tal dinâmica de grupo para a coesão grupal e o ensino e aprendizagem de ciências em tais ambientes escolares.

Palavras-chave: Tecnologia e educação. Trabalho colaborativo. Aprendizagem baseada no uso de computadores. Educação em ciências. Análise do discurso.

1. Tradução: Bruno de Oliveira-Jayme. 


\section{Computer collaborative work in the elementary science classroom: The making of monopolization}

In the present study, we articulate how the nature of students' interactions during computer collaborative work (CCW) is not only mediated by their physical arrangement within the group, but it also contributes to the emergence of monopolization. Using a socio-cultural theoretical approach to learning in conjunction with discourse analysis to investigate the verbal and non-verbal exchanges amongst members of a working group in an elementary science classroom, we discuss the negative implications of this unique type of group dynamic to group cohesion and science teaching and learning in such computer-based school environments.

Keywords: Technology and education. Collaborative work. Computer-based learning. Science education. Discourse analysis.

\section{Clases de ciencias en laboratorios de informática: una construcción discursiva do monopolio participativo}

En el presente estudio examinamos como la naturaleza de los estudiantes durante una actividad escolar que incluye el uso de computadoras no solo es mediada por su arreglo físico dentro del grupo, como también contribuye al comienzo de monopolio. Utilizando la teoría sociocultural del aprendizaje y el análisis del discurso como herramientas para el análisis e interpretación de los intercambios verbales y no-verbales entre los miembros del grupo de trabajo en el aula de la escuela primaria, presentamos las implicaciones negativas de este tipo de dinámica del grupo en referencia a la cohesión grupal y la enseñanza y aprendizaje en ciencias en dichos ambiente escolares.

Palabras clave: Tecnología y educación. Trabajo colaborativo. Aprendizaje basado en el uso de computadoras. Enseñanza de las ciencias. Análisis del discurso. 


\section{Introdução}

Imagine o seguinte: um grupo de quatro a cinco alunos e alunas dividem um único computador durante uma aula de ciências no laboratório de informática da escola. Esta é provavelmente uma situação cada vez mais comum em muitas salas de aula nos dias de hoje, já que computadores são utilizados na educação, por mais de vinte anos, com o objetivo de engajar alunos e alunas em atividades escolares (van Joolingen; de Jong; Dimitrakopoulou, 2007). De fato, “usar ou não computadores na aprendizagem, não é mais uma questão na educação. A atual questão está em garantir que computadores sejam utilizados de forma eficaz para criar novas oportunidades de ensino e aprendizagem" (Valanides; Angeli, 2008, p. 3).

Entre os muitos usos possíveis para os computadores em sala de aula, é esperado um aumento da produtividade e aprendizagem pelos seguintes fatores: permite a redução progressiva de determinadas tarefas a um tamanho administrável e oferece maior estímulo para alunos e alunas; b) simula fenômenos que de outra forma não estariam prontamente disponíveis, no mundo natural, à investigação e à observação por parte de alunos e alunas; c) proporciona um ambiente com múltiplas (não lineares) formas de representação (ex., texto, áudio e vídeo) e incentiva alunos e alunas a buscarem seus próprios meios de aprender de forma mais criativa (Moos; Azevedo, 2009). Em outras palavras, computadores podem apoiar a colaboração entre alunos e alunas, fazendo com que assumam a responsabilidade de seu próprio aprendizado. Portanto, os alunos e alunas envolvem-se ativamente no processo de negociação de ideias, a fim de melhorar a aprendizagem de novos e relevantes saberes (van Joolingen et al., 2005; Marbach-Ad; Sokolove, 2000; Calderón; Hertz-Lazarowitz; Slavin, 1998).

Por outro lado, a pesquisa empírica na área da educação tem produzido evidências inconclusivas em relação à eficácia da utilização de computadores em salas de aula (Norris; Smolka; Soloway, 2000; Kuljhgik, 1994). Em outras palavras, apenas equipar salas de aula (de ciência) ou professores com computadores não conduz necessariamente a um enriquecimento espontâneo de experiências na aprendizagem (Papadouris; Constantinou, 2009), especialmente considerando o tamanho das turmas atuais, a composição e o número de máquinas disponíveis por aluno (Roberts; McInnereny, 2004; Egan, 1997). Portanto, pesquisadores têm focado sua atenção para os processos cognitivos, metacognitivos e motivacionais que os e as aprendizes usam quando trabalham nesses tipos de ambientes de aprendizagem (Lindgren; Schwartz, 2009; Azevedo, 2005). Um aspecto comumente ignorado em tais estudos é como as interações entre os alunos e alunas podem oferecer uma melhor visão sobre o desenvolvimento de suas atividades (Louca; Zachariah, 2008). 
No presente trabalho, buscaremos demonstrar como a natureza das interações verbais e não verbais entre alunos e alunas durante o trabalho colaborativo e mediado por computador (TCMC), em uma aula de ciências, não apenas é mediada pela disposição física dos membros do grupo, mas também contribui para o surgimento de monopolização das ferramentas de trabalho. Discutiremos também as implicações negativas desse tipo único de dinâmica para a coesão do grupo. Como exemplo, olhemos o seguinte diálogo entre membros do grupo, que aconteceu durante uma sessão de informática em que os participantes editavam um vídeo de ciências sobre uma aula de campo, onde estiveram filmando algumas semanas anteriores. Neste ponto da interação do grupo, os participantes já haviam selecionado os segmentos de imagens que seriam incluídas no vídeo final. Portanto, como próximo passo da produção de vídeo, os alunos precisavam decidir quais transições deveriam ser adicionadas entre as cenas. 0 grupo tem cinco membros no total, mas apenas três (Maria, Avril e Tara²) participam nesta parte da conversa ${ }^{3}$ :

\begin{tabular}{|l|r|c|l|}
\hline & 01 & Maria: & Espere, temos que fade out ${ }^{4}$, lembra? Vamos colocar fade out lá. \\
\hline$\rightarrow$ & $\mathbf{0 2}$ & Avril: & -Posso fazer alguma coisa? \\
\hline & 03 & Tara: & Não. Não. \\
\hline & 04 & Maria: & Sim, a gente decidiu, lembra que a gente queria fade out? \\
\hline$\rightarrow$ & $\mathbf{0 5}$ & Tara: & Ah é, fade -out. \\
\hline$\rightarrow$ & $\mathbf{0 6}$ & Avril: & -Posso fazer alguma coisa? \\
\hline
\end{tabular}

Neste trecho, Maria pede a Tara que ela espere, uma vez que ainda há um efeito de transição a ser adicionado ("Espere, temos que fade out" [linha 01]). Maria também indica que o grupo já havia decidido anteriormente qual efeito de transição seria usado (“Lembra?" [linha 01]). Usando uma frase imperativa, Maria parece determinar sua próxima ação ("Vamos colocar fade out lá” [linha 01]). Avril expressa vontade de

2. Foram usados pseudônimos para garantir a anonimidade dos participantes.

3. Utilizaremos as seguintes convenções de transcrição: _ e _ setas apontando para cima e para baixo indicam aumento e diminuição da voz respectivamente; $(3,0)$ equivale ao tempo de uma pausa em segundos; (.) pausa perceptível de menos de 0,10 segundos; $<\langle p\rangle>$-menor do que o volume de voz normal; (( )) parênteses duplos cercam comentários dos transcritores; [ colchetes em linhas consecutivas indicam o início de uma sobreposição do discurso; ^ aumento de voz em apenas uma sílaba em uma palavra.

4. Fade out: Procedimento que faz com que a imagem na tela desapareça num fundo branco ou preto. 
contribuir com o projeto fazendo uma pergunta a Tara (que se senta bem em frente ao computador): "Posso fazer alguma coisa?" [linha 02]. Tara, além de não responder ao pedido de Avril, responde negativamente à sugestão de Maria sobre a adição da transição (ou seja, fade out): "Não, não [têm que fade out]" [linha 03]. Maria insiste no compromisso que o grupo já havia feito com a transição fade out: "Sim, a gente decidiu, lembra que a gente queria fade out?" [linha 04]. Tara agora parece lembrar o seu acordo: "Ah é, fade out" [linha 05]. Mais uma vez, Avril repete seu pedido: "Posso fazer alguma coisa?" [linha 06], evidenciando que ela não tinha recebido uma resposta adequada ou qualquer reação do grupo ao seu pedido anterior.

Neste primeiro episódio, uma aluna (Tara) está sentada mais perto do computador do que as outras duas alunas (Avril e Maria). A posição de Tara em relação ao computador e às outras alunas, em parte, pode explicar porque Maria e Avril precisam da permissão de Tara para contribuírem com o trabalho. Em outras palavras, Tara tem um acesso mais direto ao computador e, consequentemente, ao software de edição de vídeos, fato que lhe permite monopolizar as ferramentas de trabalho lou seja, computador e software de edição). Avril não apenas tem que pedir para participar nessa parte da atividade, mas a ela também é negada a permissão para fazer isso. Além disso, outros membros do grupo ajudam a perpetuar o controle de Tara sobre a atividade por não protestarem contra o comportamento dela (nota-se que não foi especificado por nenhum membro do grupo ou instrutor qual seria o nível de participação de cada membro do grupol.

Finalmente, aprendemos com este episódio que monopolização não é um atributo de indivíduos, mas sim um recurso que pode emergir através de interações sociais em situações de trabalho colaborativo. Como tal, monopolização e suas consequências durante TCMC ainda estão a ser melhor compreendidas no campo da educação. Neste contexto, este estudo contribui para a compreensão da diversidade dos problemas que ocorrem quando os alunos trabalham em grupos em um ambiente de informática.

\section{Perspectivas discursivas e socioculturais no trabalho colaborativo e mediado por computador}

Como nosso interesse é compreender as interações dos alunos e alunas (comunicação verbal e não verbal) dentro do contexto cultural, institucional e histórico onde essas interações acontecem, o quadro teórico que usamos é baseado nos conceitos da teoria da atividade (Leont 'ev, 1981). Esta teoria foi desenvolvida a partir da obras de Lev Vygotsky (1978) e apresenta o seguinte conceito fundamental: os seres humanos não agem diretamente em direção ao objeto de suas ações, mas eles dependem de 
suas interações sociais. Por exemplo, a fim de produzir um vídeo sobre uma aula de campo de ciências, olals estudantes dependem de todos os integrantes do grupo, do computador e seus componentes, e toda a comunicação (verbal e não verbal) que acontece entre eles. Em outras palavras, a teoria da atividade é baseada nos princípios de uma dialética materialista, no sentido de que os seres humanos são parte de uma relação dialética entre o sujeito (os próprios humanos) como unidades biológicas e sua própria cultura humana (objeto). Desta forma, a teoria da atividade nos ajudou a evitar suposições sobre o que se passa dentro da cabeça dos alunos, porque as suas ações são sociais e históricas, sendo situadas no contexto onde elas acontecem.

Nosso trabalho de análise está enraizado na análise discursiva, o que representa uma tentativa metodológica de se afastar do campo da psicologia cognitiva e comportamental (tradicional), para seguir uma perspectiva mais social sobre o estudo de interações (Edwards; Potter, 1992), abrindo desta maneira um grande potencial para a pesquisa na área da educação (Oliveira-Jayme; Reis; Roth, 2010; Reis, 2009). A análise do discurso, como aplicada neste estudo, centra-se na forma como os participantes utilizam recursos discursivos para dar sentido a suas ações diante daqueles que participam das mesmas atividades. Esta perspectiva não individualista do discurso requer que nós, pesquisadores, trabalhemos apenas com o que os participantes disponibilizam (comunicação verbal e não verbal) durante suas interações discursivas. Por exemplo, durante as entrevistas com participantes, evita-se trabalhar com as entidades presumidas da mente (conceitos, informações), que são inacessíveis para observadores (Hammersley, 2003). Em linha com a teoria da atividade, conforme discutido acima, a análise do discurso também assume que a participação em qualquer atividade humana é sempre mediada por fatores sociais, históricos e culturais.

A terminologia "trabalho colaborativo e mediado por computador (TCMC)" referese ao aprender e aos saberes associados às interações de participantes em um grupo de trabalho (Lave; Wenger, 1991). Estudos têm sugerido que, em TCMC, a apropriação de trabalho e controle dos instrumentos de trabalho devem mudar entre os membros do grupo para tornar a colaboração mais democrática (Blatchord et al., 2003). Ou seja, em uma situação em que os alunos trabalham juntos, compartilhando um único computador, eles deveriam se revezar ao interagirem com o computador. No entanto, como visto no episódio anterior, este não é sempre o caso. A partir de uma perspectiva discursiva de análise, quando os membros de um grupo de trabalho discutem sobre as atividades em que estão envolvidos, eles, ao mesmo tempo, tornam disponível ao grupo suas próprias perspectivas e entendimentos sobre a atividade em questão. Portanto, ao interagirem, os alunos e alunas coordenam suas conversas de maneira a construir um entendimento conjunto da atividade que estão envolvidos. Caso contrário, 
se apenas um dos indivíduos dentro do grupo monopoliza as ferramentas de mediação lou seja, computador e software de edição), as interações dos alunos e alunas podem tornarse descoordenadas, comprometendo, assim, a qualidade do produto final da atividade.

Em outras palavras, em situações de TCMC, os alunos deveriam entender como o trabalho em equipe deve ser conduzido, por exemplo, revezando-se com as ferramentas de trabalho. Além disso, é importante que eles possuam as habilidades sociais necessárias para o trabalho colaborativo (Johnson et al., 1997), tais como ouvir uns aos outros durante a discussão em grupo, reconhecendo ideias um dos outros e considerando as ideias alheias, sugerir novas ideias livremente e resolver seus conflitos de maneira democrática. Caso contrário, um baixo nível de interação entre o(a)s participantes pode indicar a falta de algumas dessas habilidades sociais, senão todas, o que pode gerar confusão e ansiedade do grupo como um todo (Miller; Trimbur; Wilkes, 1994). Se este for o caso, os alunos podem negociar suas ideias e sugestões para o trabalho de uma maneira diferente daquela esperada se tais habilidades sociais estivessem presentes. No primeiro diálogo, Tara assumiu o comando de filtrar as discussões do grupo antes de processá-las no computador. Nesse sentido, Tara monopoliza o computador, afetando o conteúdo e a forma do produto final. A partir de uma perspectiva sociocultural, o computador medeia todas as interações dos participantes do grupo e as colaborações individuais dos alunos que estão envolvidos num contexto mediado por computador (Staarman; Aarnoutse; Verhoeven, 2003), portanto, como ferramentas na atividade humana, os computadores não podem ser vistos como unidades separadas dentro dessas atividades. Desta forma, computadores são considerados mediadores de saberes, assim como os saberes medeiam o uso dos computadores.

Nosso banco de dados para a pesquisa surgiu a partir de 15 sessões de informática, filmadas por estes pesquisadores - particularmente por Bruno de Oliveira Jayme e Giuliano Reis - durante um período de seis meses na escola de ensino fundamental Blueberry Field Elementary School no ano de 2006. Estas sessões de informática acumulam 400 minutos de dados. A escola está localizada em uma área urbana de British Columbia, no Canadá. Para este estudo, foram filmados 25 alunos e alunas e seus professores em sala de aula da quinta série do ensino fundamental. Embora houvesse quatro outros grupos que trabalhavam na sala, nós nos concentramos nas interações de apenas um grupo, para exemplificar o fenômeno da monopolização em contextos de aulas de ciências. Porém, nossas descobertas não devem ser tomados como ocorrências isoladas. Pelo contrário, nossos resultados ilustram as várias possibilidades disponíveis para todos aqueles em ambientes semelhantes. Da mesma forma, os episódios incluídos nas sessões seguintes não são nem um reflexo dos métodos empregados pelo professor, nem um reflexo do saber sobre ciências de seus alunos e 
alunas; pelo contrário, nossa pesquisa se preocupou com situações reais em que pessoas reais podem encontrar-se.

Nas sessões seguintes, ilustramos como a monopolização é um fenômeno social e discursivamente alcançado e mantido dentro de TCMC no contexto de uma aula de ciências do ensino fundamental. Em outras palavras, procuramos demonstrar como a natureza da conversa dos alunos dentro dos grupos TCMC pode ter implicações imprevisíveis para o ensino e aprendizagem de ciências nas escolas. Descreveremos primeiro o arranjo físico dos alunos em torno do computador, bem como em relação aos seus colegas de trabalho, e como este posicionamento favorece uma certa direcionalidade das informações geradas pelos membros do grupo para o computador e viceversa. Em seguida, apresentaremos algumas especificidades sociais das interações dos alunos, incluindo gestos emblemáticos (comunicação não verbal), contato físico e comunicação verbal, que permitiram o surgimento de monopolização neste contexto de uma aula de ciências.

\section{Monopolização em uma atividade de ciências no laboratório de informática}

Poucas semanas após a aula de campo de ciências, quando os alunos e alunas tiveram a oportunidade de filmar até 30 minutos de sua experiência, esses mesmos alunos e alunas começaram a editar seus vídeos no laboratório de informática da escola. Lá, eles formaram grupos de trabalho, com os mesmos colegas que trabalharam juntos durante a aula de campo (Figura 1$)^{5}$.

Figura 1. (A) Arranjo físico de um grupo TCMC (PC- Computador, A-Avril, F-Fernando, TTara, C-Casey, M-Marial trabalhando num projeto de ciências que envolve a produção de um vídeo. (B) Vista aérea detalhando a posição dos alunos e alunas (círculos) entre si e em relação ao computador.
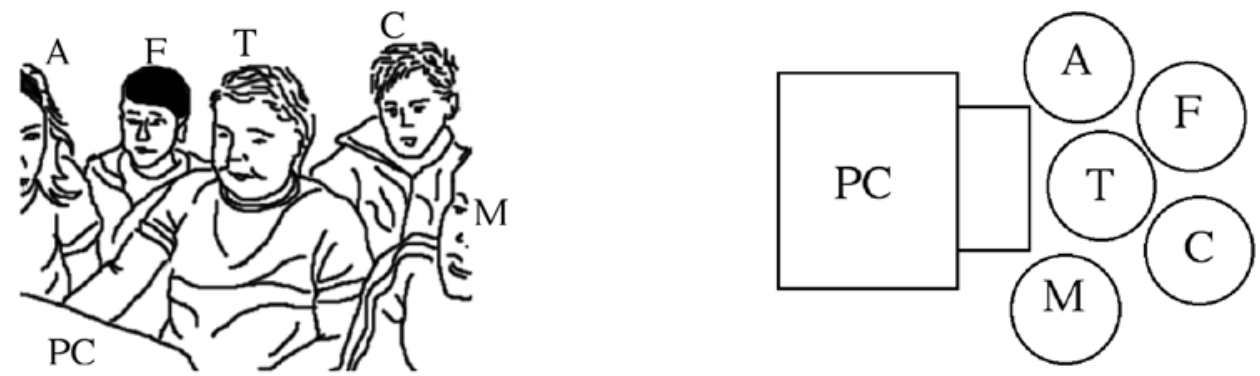

5. As imagens a seguir foram extraídas de fotos tiradas durante as atividades no no laboratório de informática e representam os participantes neste projeto 
Como mostra a Figura 1A, Tara (T) senta-se logo em frente à tela do computador (PC), enquanto todos os outros alunos e alunas estão organizados em torno dela. Maria (M) e Avril (A) sentam-se ao lado direito e esquerdo de Tara, respectivamente, enquanto Fernando (F) e Casey (C) sentam-se atrás de Tara, como detalhado na Figura 1B. Dadas as suas proximidades com relação ao computador, Tara, Maria e Avril poderiam alcançar o computador mais facilmente do que Casey e Fernando, que se sentam mais distantes do computador, e atrás de Tara, Maria, e Avril.

Por meio de suas interações, o grupo alcançou um entendimento mútuo sobre o que precisava concluir no trabalho - e tinha uma maneira bem particular de fazê-lo (Figura 2). Como eles chegaram a um entendimento mútuo, Tara la aluna sentada mais perto do computador) deu entrada a todas as ideias do grupo no computador. Portanto, as ideias e sugestões dos alunos para o projeto tiveram que passar por um único aluno (Tara), antes de serem finalmente processadas (materializadas) no computador. Em outras palavras, as sugestões dos alunos e alunas foram transformados (como um resultado de sua atividade) em um formato de vídeo digital. Notadamente, este padrão de comunicação inicialmente contribuiu para que os alunos entrassem em consenso sobre a conversa que ocorreu entre eles, o que também é considerado um atributo importante na conversa científica entre os alunos e alunas (Goodwin, 1986).

Figura 2. Diagrama que ilustra alunos engajados em grupo TCMC. As informações trocadas pelos alunos e alunas (indicadas pelas setas) primeiramente passam por Tara, antes de serem processadas no computador. 0 indivíduo responsável em processar essas informações no computador, obviamente, é aquele sentado mais próximo ao computador.

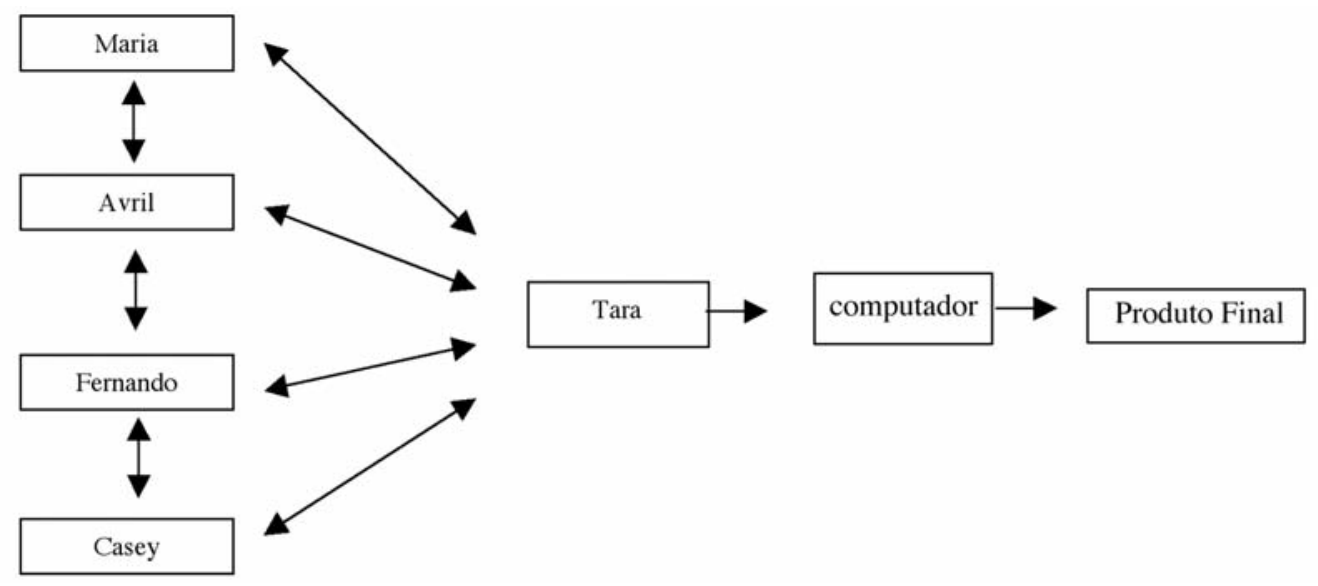


Em resumo, o arranjo físico dos alunos e alunas em torno do computador gerou um caminho exclusivo de ideias e informações entre os participantes antes de chegar ao computador. 0 arranjo físico dos alunos e alunas em torno do computador parece ter facilitado a monopolização das ferramentas de mediação (por exemplo, mouse, tela do computador e tecladol por um dos membros do grupo, isto é, aquele com mais fácil acesso a eles. Adicionalmente, o fato de que nenhum aluno ou aluna do grupo em nenhum momento contestou esta organização, apenas contribuiu para a monopolização. Portanto, como o trabalho progredia, esta disposição física dos participantes nos seus postos de trabalho mostrou-se problemática.

A postura física dos alunos e alunas também desempenha um papel central em relação ao acesso ao computador. Neste caso, o computador representa um ponto focal comum que pode ser tocado, apontado, bem como referido por meio de comunicação verbal. Tais comportamentos facilitam e também medeiam as interações entre os alunos (Roth; Woszczyna; Smith, 1996). No entanto, como indicado acima, o arranjo físico dos membros do grupo em torno do computador pode interferir na forma como eles se movimentam dentro do seu grupo de trabalho. Em outras palavras, dependendo da maneira com que os indivíduos se movem em frente ao computador, estes mesmos indivíduos podem restringir a participação de seus(suas) colegas na atividade, bloqueando a visão deles ou delas, o que pode diminuir a participação deles ou delas nas ações. Além disso, os movimentos corporais dos(as) colegas durante o trabalho colaborativo são evidências de que alunos e alunas estão coletando informações de outros membros, o que significa que, por meio de seus movimentos corporais, alunos e alunas demonstram o seu grau de envolvimento, bem como seus estados emocionais para seus companheiros de trabalho.

No caso de Tara (figura 3), ela se senta diretamente em frente ao computador, enquanto os outros quatro membros do grupo sentam-se ao seu redor. Para qualquer lado que Tara movimenta o seu corpo, ela se dispõe diretamente em frente à tela do computador ou em frente aos seus colegas. Desta forma, há sempre a possibilidade, intencional ou não, de que Tara fisicamente bloqueie a visão de Casey (C) e Fernando (F), que estão sentados atrás dela e ainda mais distantes do computador. Na posição específica de Casey, é mais difícil para ele chegar a qualquer um dos componentes do computador, já que ele fica mais distante da máquina e de seus periféricos. Por exemplo, a Figura 3B ilustra Tara movimentando seu corpo em direção a Casey para falar com ele. Ao fazê-lo, ela identifica a presença de Casey no grupo e sua vontade de contribuir, mas acaba bloqueando a visão de Fernando, que se senta ao lado oposto; assim, Tara limita a participação deste. A figura 3C ilustra o momento em que Casey tem sua visão bloqueada por Tara, que agora conversa com Fernando. Enquanto os 
movimentos do corpo de Tara aumentam sua interação com Casey e Fernando, também limita suas (Casey e Fernando) interações com o computador e as interações de um com o outro.

As frequentes movimentações de Tara em frente ao computador exemplificam sua autonomia sobre seus(suas) colegas: ao girar o seu corpo para falar com seus(suas) colegas de grupo, sem desocupar seu lugar, ela é capaz de coletar informações de seus companheiros ou companheiras e processá-las, ela mesma, no computador. Mais uma vez, a autonomia de Tara em relação aos seus(suas) colegas de trabalho pode ser explicada por sua maior proximidade do computador, comparada à de seus(suas) colegas. Não podemos presumir que Tara movimente o seu corpo conscientemente para bloquear a visão de seus(suas) colegas, mas nossos resultados indicam que, ao movimentar-se, ela inibe a participação dos outros alunos e alunas.

Figura 3. Os movimentos físicos de Tara podem interferir na participação de seus colegas nas atividades do grupo.
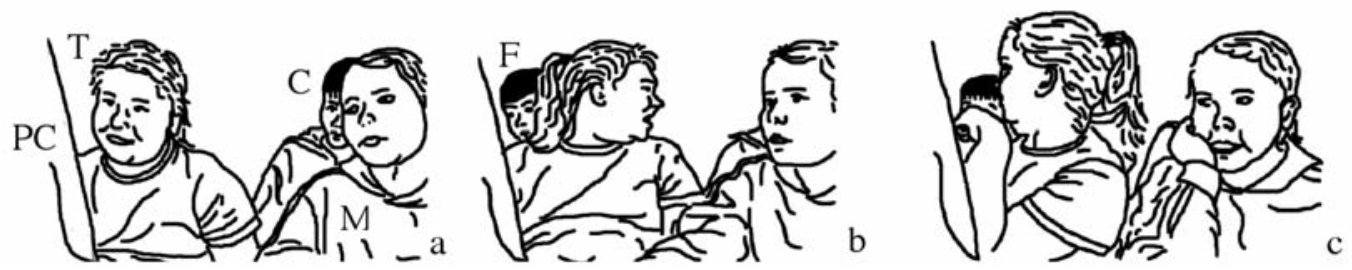

Gestos emblemáticos ${ }^{6}$ desempenham determinadas atividades sociais. Eles são, na verdade, ações discursivas e desempenham um limite certo de funções. Por exemplo, gestos emblemáticos realizam promessas, juramentos, etc. Também podem ser usados em saudações, comandos, solicitações, insultos, ameaças, busca de proteção, manifestação de desprezo ou de medo, e assim por diante (McNeill, 1999). Dedos polegares apontando para cima, dependendo do contexto, indicam "positivo". Dedos polegares apontando para baixo podem significar algo negativo. Todos estes são exemplos de gestos emblemáticos. Em uma das sessões de informática, quando os alunos terminavam de transferir seus vídeos para o computador e estavam prontos para a seleção de videoclipes que usariam em seus projetos finais, os alunos interagem novamente.

6. Para exemplificar gestos emblemáticos, Neill (2000) usa o sinal de o.k. - produzido a partir de um círculo formado com o dedo indicador e o dedão, enquanto os outros dedos se estendem. Este gesto emblemático pode ou não acompanhar um discurso. Os gestos emblemáticos, como uma palavra, assumem forma fonológica. 
Figura 4. Tara coloca o seu dedo indicador sobre sua boca (gesto emblemático), pedindo a sua colega de grupo para ficar quieta.

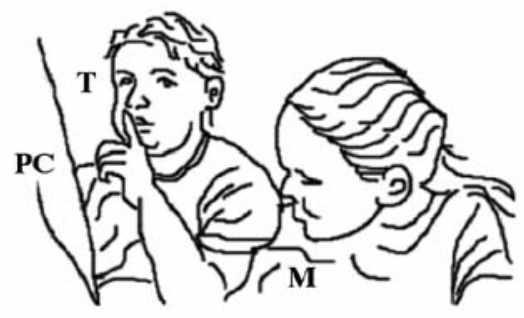

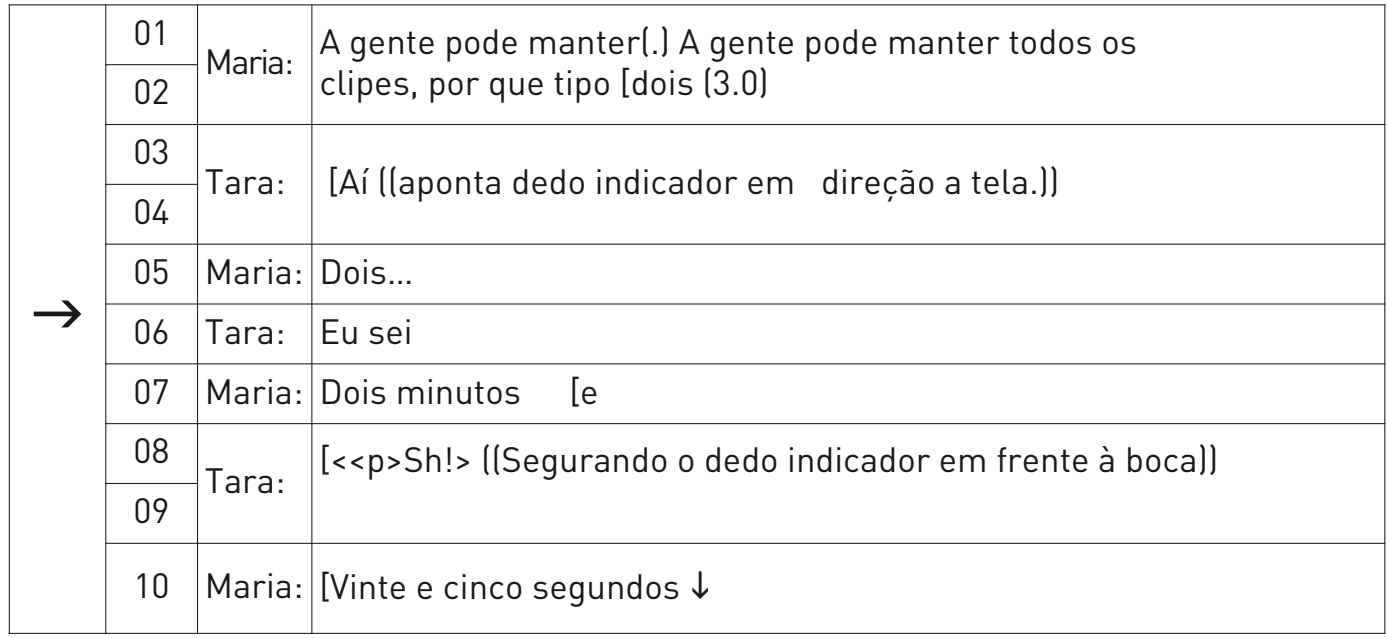

Neste último trecho, Maria diz que eles podem manter todos os clipes que foram previamente transferidos para o computador, tendo em vista que naquele momento já tinham atingido o tempo solicitado para a extensão final de seus projetos, ou seja, dois minutos (linhas 01 e 02). No entanto, Maria não termina sua frase, porque Tara corta seu discurso, dizendo "aí" (linha 03), enquanto aponta o seu dedo indicador para a tela do computador. Ao fazê-lo, qualquer coisa que Tara mostrava a Maria estava sendo exibida na tela do computador. Maria agora termina sua frase, dizendo "dois" (linha 05), o que significa que eles podem manter todos os vídeos em seu projeto final, pois todos os vídeos que têm já somam dois minutos de duração. Tara concorda com Maria: afirma que sabe que eles podem usar os clipes sugerido por Maria (linha 06). Em seguida, ainda se referindo ao comprimento de seus videoclipes, Maria diz "dois minutos e" (linha 07), mas mais uma vez Tara interrompe Maria com um pedido de silêncio, que ela realiza de forma muito particular. Tara interrompe a fala de Maria 
com duas ações físicas. Em primeiro lugar, ela aponta o dedo indicador em direção à tela do computador (ação repetida pela segunda vez). Em seguida, Tara traz o mesmo dedo para a frente de sua boca, executando assim um gesto emblemático, significando (e exigindo) silêncio. Ao fazê-lo, Tara indica para Maria que ela deveria estar em silêncio naquele momento. 0 gesto emblemático usado por Tara é ilustrado na figura 4, que detalha Tara com seu dedo indicador sobre boca. Nesse momento, Tara não diz uma única palavra, além da interjeição "shh". No entanto, por causa do gesto emblemático de Tara, Maria nem termina de dizer o que falava anteriormente. Em vez de escolherem os clipes que seriam parte do projeto final, assim como Maria sugerira no início desse episódio, Tara olha para a tela do computador e não toma nenhuma medida por um período de 53 segundos. A ação de Tara lgesto emblemático, seguido de seu olhar para a tela do computador) marca o fim da discussão sobre o tema, porque eles não falam sobre as sugestões de Maria. Como resultado, Maria tem sua participação regulada pela interrupção repetida de Tara. Nesse momento, Tara conseguiu não ser interrompida enquanto tomava decisões sobre os clipes que usaria. Ela conseguiu não ser interrompida por meio de um gesto emblemático e, mais uma vez, manteve o controle do grupo durante a atividade em questão. Esse episódio poderia ter terminado de forma diferente, se Maria, em vez de apenas aceitar o pedido de Tara, tivesse insistido em debater a duração do seu videoclipe. Uma estratégia semelhante ocorreu quando o grupo selecionava as transições que seriam usadas entre os clipes. Tara, ainda sentada à frente do computador, e Maria, que estava ao lado esquerdo, discutem os tipos de transições disponíveis no software de edição de vídeos. Nesse momento, um terceiro aluno, Casey, pergunta ao grupo se ele poderia ajudá-las.

\begin{tabular}{|c|c|c|c|}
\hline$\rightarrow$ & 01 & Casey: & $<<$ p $>$ Posso ajudar? $>$ \\
\hline & 02 & Maria: & Quase pronto. \\
\hline & 03 & Tara: & Oh, está pronto. \\
\hline & 04 & Maria: & Vamos apenas assistir. \\
\hline & 05 & Maria: & Alí \\
\hline & 06 & Tara: & Yehl.Jh. \\
\hline$\rightarrow$ & 07 & Casey: & $<<p>$ Me deixa. Me deixa ajudar? $>$ \\
\hline$\rightarrow$ & 08 & Tara: & Casey, vocês já estãl.)o. \\
\hline
\end{tabular}


Casey, que se senta atrás de Maria e Tara, indaga-lhes (com um tom muito baixo em sua voz) se ele pode ajudar (linha 01). Ao fazer tal pedido, Casey faz com que seus(suas) colegas percebam sua presença física no grupo, além de declarar sua intenção de se envolver mais diretamente com as atividades. Contudo, Tara não the direciona a palavra e ignora o seu pedido para ajudar no trabalho. Enquanto isso, Maria também não responde imediatamente ao pedido de Casey; em vez disso, ela diz a Tara que estão para finalizar a atividade (linha 02). Tara concorda com Maria, quando aquela afirma que o vídeo está pronto (linha 03). Maria convida Tara para ver o vídeo (linhas 04, 05, e 06). Pela segunda vez, Casey demonstra a sua intenção em ajudar, quando ele repete o seu pedido, com uma voz muito baixa: "Me deixa. Me deixa ajudar" (linha 07). Tara finalmente responde ao pedido de Casey, ao dizer: "Casey, vocês já estão" (linha 08). Mesmo Casey fazendo os dois pedidos para ajudar na atividade, Tara fala com o colega como se ele estivesse expressando o desejo de participação em um grupo maior que está insatisfeito, quando ela usa o pronome pessoal "vocês" (linha 08). No primeiro caso, Casey coloca a questão de uma forma que evoca a ideia de uma oferta para ajudar. No segundo caso, ele está pedindo permissão para ajudar, reforçando assim a sua vontade de contribuir originalmente expressa na linha 01. Tara, no entanto, referese ao grupo como um todo, quando ela responde: "Vocês já estão." Em outras palavras, de acordo com Tara, não importa o que os outros membros estão fazendo, ou o quanto eles haviam contribuído para o trabalho até aquele momento, pois a resposta de Tara é indiferente, na medida em que ela afirma que o que quer eles queriam fazer já está sendo feito, ou seja, não há razão para fazer algo diferente (eles já estão ajudando). Neste último episódio, um dos membros do grupo pede permissão aos seus(suas) colegas para ajudar num trabalho que deveria ter sido feito de forma colaborativa. Adicionalmente, a dinâmica do grupo como um todo gera uma divisão de trabalho, como apresentado anteriormente, porque cada indivíduo do grupo aceita que Tara permaneça com o controle do computador durante toda a sessão de informática. Quando Casey pediu permissão à colega que se senta mais próxima ao computador (Tara), ele (re)afirmou o controle de Tara sobre o computador.

Em seguida, apresentamos mais um episódio, que ilustra como o contato físico entre os membros do grupo pode também mediar a monopolização dentro do contexto de um grupo de TCMC. 0 seguinte episódio aconteceu no final dessa sessão de informática, quando Tara e Maria estavam discutindo as etapas finais da sua produção de vídeo. 
Figura 5. Tara empurra a mão de Maria, quando Maria alcança o mouse do computador (PC).

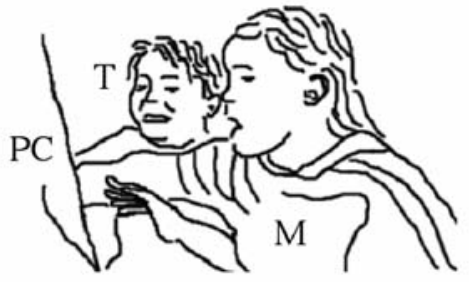

\begin{tabular}{|l|c|l|}
\hline 01 & Tara: & $\uparrow$ Não:: \\
\hline 02 & Maria: & Eu estou ap ^nas fazendo um negócio \\
\hline 03 & Tara: & Maria, não $\uparrow^{`} \downarrow$ \\
\hline
\end{tabular}

Tara cotinua sentada à frente do computador, enquanto Maria senta-se ao seu lado esquerdo. Maria (M), sem dizer nenhuma palavra, alcança o mouse do computador com a mão direita. Tara (T) olha para ela e diz "não" (linha 01). Maria discute, alegando que estava fazendo alguma coisa (linha 02), e, pela segunda vez, Maria alcança o mouse. No entanto, a ação de Maria é interrompida por Tara, que empurra as mãos de Maria, fazendo com que Maria solte o mouse. Este contato físico entre as duas alunas é detalhada na figura 5. A ação de Tara é seguida pela sentença: “Maria, não” (linha 03). Depois de ter sua participação inibida duas vezes por Tara, Maria não reage à imposição, permitindo a Tara que continue usando o computador.

Curiosamente, quando Maria inicialmente externa sua intenção de usar o mouse do computador, alegando que "estava apenas fazendo um negócio", ela estava resistindo lou tentando quebrar) o padrão de monopolização. Em outras palavras, esta última ação de Maria pode ser vista como um exemplo de resistência entre os participantes do grupo - um fator importante nas interações dos alunos e alunas (Brown; Palincsar, 1989). Mesmo que alguma resistência possa ter ocorrido entre os membros do grupo, devido à monopolização dos instrumentos de trabalho e da atividade como um todo, o trabalho em grupo era o objetivo principal deste projeto, como exemplificado no pedido de Casey para ajudar no trabalho coletivo.

\section{Discussão e conclusão}

Em nosso estudo, verificou-se que os alunos e alunas que estavam sentados mais distantes do computador engajaram-se menos na ativamente, ou engajaram-se em conversas paralelas com outros membros de outros grupos, o que contribuiu para que a situação permanecesse inalterada (e incontestável). Em termos de tamanho de grupo, estudos anteriores já haviam sugerido que, quando o número de indivíduos é superior 
a quatro membros, alguns indivíduos podem ser excluído das ações. Além disso, ressaltamos que existem outras interações sociais, tais como os movimentos corporais, que bloqueiam a visão dos colegas de grupo, além de gestos emblemáticos e comunicação verbal entre os participantes, que também contribuem para a exclusão de colegas de grupo em certas atividades.

Pesquisas anteriores também têm demonstrado que, quando convidados a trabalhar de forma colaborativa, grupos de estudantes gastam quase a metade do tempo disponível lidando com aspectos emocionais decorrentes de suas interações sociais (Schmuck; Schmuck, 1979). Somando-se a essas ideias, nosso estudo revela que a monopolização dos instrumentos de trabalho durante TCMC também é fator que contribui para conflitos durante o trabalho colaborativo, quando participantes lidam não apenas com suas próprias emoções, mas também com o estado emocional de seus(suas) colegas de trabalho. Uma altercação entre os estudantes no final do projeto sugere decepção por parte de alguns membros do grupo por causa da monopolização dos instrumentos de trabalho.

Neste artigo, nós primeiramente descrevemos o arranjo físico de grupos de TCMC ao redor do computador e como este arranjo físico propicia um caminho único das ideias dos alunos para um único indivíduo e, em seguida, para o computador. Em seguida, demonstramos como a monopolização das ferramentas de trabalho é gerada dentro de TCMC, sendo um resultado da combinação de diversos tipos de interação que podem ocorrer entre os participantes, no sentido de que apenas um aluno ou aluna tenha acesso ao computador, enquanto outros são limitados em seus níveis de acesso. Nosso estudo é embasado no pressuposto de que, quando os alunos estão trabalhando de forma colaborativa, cada indivíduo dentro do grupo de trabalho é responsável por tornar a situação o que é, dependendo de como eles interagem. Assim, usamos episódios de alunos interagindo, em um ambiente de informática, para exemplificar o fato de que a monopolização dentro de uma aula de ciências e em TCMC é dependente das interções entre os alunos, em vez de um atributo possuído por indivíduos. Dessa forma, nosso estudo contribui para a literatura no campo do ensino e aprendizagem de ciências, bem como para a compreensão dos diversos problemas que podem ocorrer quando alunos trabalham de forma colaborativa numa aula de ciências. 0 fato de que um ambiente de informática pode oferecer a restrição de possibilidades para o aprendizado daqueles que não têm acesso direto ao computador (determinar os níveis desiguais de envolvimento dos colegas na atividade) poderia soar contraintuitivo para alguns (Kaput, 1992). Entretanto, o valor de nossa contribuição reside, em parte, em ter sido capaz de demonstrar que alguns alunos podem ter sido excluídos da atividade, em função do arranjo físico do grupo em combinação com as estratégias utilizadas pelos mesmos participantes. 
Sugerimos que o TCMC deva ser cuidadosamente planejado de forma que os alunos possam ter chances iguais de participação e gestão dos instrumentos de trabalho. Em um ambiente de informática, devido ao arranjo físico deste ambiente, diferentes indivíduos tendem a se envolver de maneira diferente na atividade em questão. Destacamos, ainda, a necessidade de futuras investigações em TCMC, para proporcionar uma nova visão sobre as formas de desenvolvimento colaborativo que possam contribuir efetivamente para o ensino e aprendizagem de ciências.

\section{Referências}

AZEVEDO, Roger. Computers environments as metacognitive tools for enhancing learning. Educational Psychologist, 40(4), p. 193-197, 2005.

BLATCHORD Peter; KATNICK, Peter; BAINES, Ed.; GALTON, Maurice. Changes in grouping practices over primary and secondary school. International Journal of Education Research, 39,p. 9-34, 2003.

BROWN, Annemarie Sullivan; PALINCSAR, Ann. Guided cooperative learning and individual knowledge, acquisition. In: L. B. Resnick (Ed.), Knowing, learning, and instruction. Hillsdale, NJ: Lawrence Erlbaum Associates, 1989, p. 393-451.

CALDERON, Muriel; HERTZ-LAZAROWITZ, Rachel; SLAVIN, Robert. Effects of bilingual cooperative integrated reading and composition on students making the transition from Spanish to English reading. Elementary School Journal, 99, p. 153-165, 1998.

EDWARDS, Derek; POTTER, Jonathan. Discursive psychology. London: Sage, 1992.

EGAN, Gerard. The skilled helper: A systematic approach to effective helping. Pacific Grove, CA: Brooks/Cole, 1997.

GOODWIN, Charles. Gestures as a resource for the organization of mutual orientation. Semiotica, 62 , p. 29-49, 1986.

HAMMERSLEY, Martin. Conversation analysis and discourse analysis: Methods or paradigms? Discourse \& Society, 14(6), p. 751-781, 2003.

De OLIVEIRA-JAYME, Bruno; REIS, Giuliano; ROTH, Wichael-Wolff (2011). Egomorphism in simple words: Discursive pedagogical artefact in/for environmental education. Journal of Education Research, 4(4). Disponível em: <https://www.novapublishers.com/catalog/product_info.php?products_id= 24164\&osCsid=b17406f46d25c202a8c2998398043182>. Acesso em: 20 ago. 2011.

JOHNSON, David; JOHNSON, Roger; MITCHEL, John; FREDRICKSON, John. The impact of conflict resolution training on middle school students. Journal of Social Psychology, 137, p. 11-21, 1997.

KAPUT, James. Technology and mathematics education. In: D. A. Grouws (Ed.), Handbook for research on mathematics teaching and learning. New York: Macmillan, p. 515-556, 1992.

KULIK, James. (Meta-analytic studies of findings on computer-based instruction. In: E. L. Baker; H. F. O'Neil Jr. (Eds.), Technology assessment in education and training. Hillsdale, NJ: Lawrence Erlbaum, p. 9-34, 1994.

LAVE, Jean; WENGER, Etienne. Situated learning: Legitimate peripheral participation. Cambridge, England: Cambridge University Press, 1991. 
LEONT'EV, Alexei Nikolaevich. The problem of activity in psychology. In: J. V. Wertsch (Ed.), The concept of activity in Soviet psychology. Armonk, NY: Sharpe, 1981, p. 37-71.

LINDGREN, Rob; SCHWARTS, Daniel. Spatial learning and computer simulations in science. International Journal of Science Education, 31(3), p. 419-438, 2009.

LOUCAS, Louca; ZACHARIAH, Zachariah. The use of computer-based programming environments as computer modeling tools in early science education: the cases of textual and graphical program languages. International Journal of Science Education, 30(3), p. 285-321, 2008.

MARBACH-AD, Gili; SOKOLOVE, Phillip. Can undergraduate biology students learn to ask higher level questions? Journal of Research in Science Teaching, 37, p. 854-870, 2000.

MCNEILL, David. Action, thought, and language. In P. Llyod; C. Fernyhough (Eds.), Lev Vygotsky: Critical assessments: Thought and language, Vol. II, p. 23-30. Florence, KY: Taylor \& Francis/ Routledge, 1999.

MACNEILL, David. Catchments and contexts: non-modular factors in speech and gesture production. In: D. McNeill (Ed.), Language and gesture. Cambridge, England: Cambridge University Press, 2000, p. 312-328.

MILLER, Judith, TRIMBUR, John.; WILKES, John. Group dynamics: Understanding group success and failure in collaborative learning. In K. Bosworth; S. Hamilton (Eds.), Collaborative learning: Underlying processes and effective techniques. San Francisco: Jossey-Bass, 1994, p. 56-73.

MOOS, Daniel,; AZEVEDO, Roger. Learning with computer-based learning environments: a literature review of computer self-efficacy. Review of Educational Research, 79(2), p. 576-600, 2009.

NORRIS, Cathleen; SMOLKA, Jennifer; SOLOWAY, Elliot. Extracting value from research: A guide for the perplexed. Techonology \& Learning, 20, p. 45-48, 2000.

PAPADOURIS, Nicos; CONSTANTINOS, Constantinou. A methodology for integrating computer-based learning tools in science curricula. Journal of Curriculum Studies, 41(4), p. 521-538, 2009.

REIS, Giuliano. Committing treason to oneself: Neglecting the effectiveness of translated activities in science and environmental education. Cultural Studies of Science Education, 4(1), p. 133-140, 2009.

ROBERTS, Tim; MCINNERENY, Joanne. Collaborative or cooperative learning? In: T. S. Roberts (Ed.), Online collaborative learning: Theory and practice. Hersey, PA: Information Science Publishing, 2004, p. 203-241.

ROTH, Michael-Wolff; WOSZCZYNA, Carolyn; SMITH, Gillian. Affordances and constraints of computers in science education. Journal of Research in Science Teaching, 33, p. 995-1017, 1996.

SCHMUCK, Richard; SCHMUCK, Patricia. Group process in the classroom. Dubuque, IA: William C. Brown, 1979.

STAARMAN, Judith; AARNOUTSE, Cor; VERHOEVEN, Ludo. Connecting discourses: Intertextuality in a primary school CSCL practice. International Journal of Educational Research, 39, p. 807-816, 2003. VALANIDES, Nicos; ANGELI, Charoula. Professional development for computer-enhanced learning: a case study with science teachers. Research in Science \& Technological Education, 26(1), p. 3-12, 2008. VAN JOOLINGEN, Wouter; DE JONG, Ton; DIMITRAKOPOULOU, Angelique. Issues in computer supported inquiry learning in science. Journal of Computer Assisted Learning, 23, p. 111-119, 2007. 
VAN JOOLINGEN, Wouter; DE JONG, Ton; LAZONDER, Ard; SAVELSBERGH, Elwin; MANLOVE, Sarah. Co-Laboratory: research and development of an online learning environment for collaborative scientific discovery learning. Computers in Human Behavior 21, p. 671-688, 2005.

VYGOTSKY, Lev Semyonovich. Mind in society: The development of higher psychological processes. Cambridge, MA: Harvard University Press, 1978.

Recebido em setembro de 2011.

Aprovado em outubro de 2012.

Bruno de Oliveira-Jayme, Ph.D. Candidate, University of Victoria, Canadá. Trabalha com pesquisa qualitativa com base nas artes, incluindo filme, teatro, fotografia e artes plásticas, aplicados à educação popular e ambiental, movimentos sociais e educação de adultos. Publicação recente: The Nature of Transformation: Environmental Adult Education (co-autoria com: CLOVER, Darlene; FOLLEN, Shirley; HALL, Budd. Third Edition. Sense Publisher, 2012 in press). Homepage: http://web.me.com/brunojayme

Giuliano Reis, Ph.D. em Educação. Assistant Professor, Faculty of Education, University of Ottawa, Canadá. Sua área de pesquisa inclui a educação de ciências e estudos ambientais em diversos contextos, incluindo mídia. Publicação recente: Egomorphism: discursive pedagogical artifact for science education lem co-autoria com: de OLIVEIRA-JAYME, Bruno; ROTH, Wolff-Michael. In: NATA, Robert [Ed.]. Progress in Education. Hauppauge: Nova Science Publisher, 2010, p. 163-172). E-mail: Giuliano.Reisquottawa.ca

Michiel van Eijck, Ph.D. em Educação pela Universidade de Amsterdam. Assistant Professor da Eindhoven University of Technology, Holanda. Tem interesse em tecnologias de informação aplicadas as ciências naturais e ao ensino e aprendizagem de ciências. Publicação recente: Cultural diversity in science education through Novelization: Against the Epicization of science and cultural centralization (co-autoria com: ROTH, Wolff-Michael. Journal of Research in Science Teaching, 48, 824-847). E-mail: m.w.v.eijck@remove-this.tue.nl

Wolff-Michael Roth, Ph.D. em Educação pela University of Southern Mississippi. Lansdowne Professor (Applied Cognitive Science) na University of Victoria, British Columbia. É especializado na teoria da atividade, ciência cognitiva aplicada e metodologia da pesquisa científica num contexto de educação em ciências, matemática e estudos ambientais. Publicação recente: Passibility: At the limits of the constructivist metaphor (Dordrecht, The Netherlands: Springer, 2011). E-mail: mrothauvic.ca 